\title{
Student Opinions on their Development of Non-technical Skills in IT Education
}

\author{
Woratat Makasiranondh (Corresponding author) \\ School of Computer and Security Science, Edith Cowan University \\ 2 Bradford Street, Mt. Lawley, WA, 6050. Australia \\ E-mail:wmakasir@our.ecu.edu.au
}

S. P. Maj

School of Computer and Security Science, Edith Cowan University

2 Bradford Street, Mt. Lawley, WA, 6050, Australia

E-mail: p.maj@ecu.edu.au

D. Veal

School of Computer and Security Science, Edith Cowan University

2 Bradford Street, Mt. Lawley, WA, 6050. Australia

E-mail: d.veal@ecu.edu.au

Received: December 21, 2010

Accepted: January 26, 2011

doi:10.5539/mas.v5n2p3

\begin{abstract}
It is recognized that non-technical or soft skills are a vital part of the IT curriculum and hence are considered to be core curriculum components, particularly in the USA and Australia and is also an important worldwide issue. An extensive analysis within an Australian university context found a mismatch between employer expectations and the university-based instruction in these skills. However, it was noted that this unpreparedness in soft skills may be because students may not have appreciated the importance of these skills - a result confirmed by this study, which used a questionnaire delivered to project students undertaking a range of IT based courses. Internships are not common in Australia and hence to address this problem guest speakers from industry are now regularly invited to give presentations to project students. Furthermore it was also found that those students who had workplace experience more fully appreciated the role of workplace soft skills than those who did not have such experience. This study clearly indicates the importance of a team based project unit for teaching soft skills. A further implication is that students need to be made aware of the importance of soft skills in the workplace as a part of their studies.
\end{abstract}

Keywords: Computer Science curriculum, Communication skills, Teamwork, Soft skills

\section{Introduction}

The IT field is subject to rapid technical developments. In order to help ensure curriculum currency, the Association for Computing Machinery (ACM) and the Institute of Electrical and Electronic Engineers (IEEE) regularly (approximately every ten years) produce recommendations for curriculum content. Recommendations for the Computer Science Curriculum 2008 were based on feedback from public consultation and various professionals and academics (ACM \& IEEE Computer Society, 2008). According to Yuan and Zhong (2010), the current ACM/IEEE 2008 recommendations were fully aligned with accreditation requirements from the Accreditation Board for Engineering and Technology (ABET). ABET was an American-based, and is now an international organization accrediting programs and curricula of universities and colleges worldwide (ABET, 2010). The consultation feedback prior to the release of the 2008 curriculum identified a number of issues that needed attention; in particular, "Communication and other transferable skills had to be addressed" (ACM \& IEEE, 2008). Hence the principles of curriculum design were developed to include additional transferrable skills; in particular the need for communication and teamwork skills.

Significantly the Australian Computer Society (ACS) has a recommended Core Body of Knowledge for 
Information Technology (Underwood, 1997). This core body of knowledge has a mandatory group of skills that specifies interpersonal communications. The British Computer Society (BCS) offers two Diplomas - IT Service Management and also IT Project Management. Both courses refer to human factors in IT as part of the taught curriculum but provide no further details (British Computer Society, 2010). Clearly interpersonal skills are an important part of the IT curriculum and must be taught.

\section{Non-technical skills or soft skills}

Different terms are variously employed and can include: soft skills, people skills, interpersonal skills and general skills. Such terms sometimes can also be included in graduate attributes. Daniels et al. (2011) have noted that the number of different names used for such skills can complicate clear definitions. Regardless of which term is used, they all describe the characteristics of a person and how that person will work with others. In most organizations staff work as part of a team. For some positions employees must interact with customers and the general public. Hence soft skills are an important aspect of both obtaining employment and succeeding in the workplace. It is generally accepted that soft skills are based on the Emotional Intelligence Quotient (EQ) or synonymously Emotional Intelligence (EI) (Schutte et al., 1998). EQ/EI is a measure of the ability to assess and control both oneself and others. This field is subject to debate however. Goleman (1998) proposed a model consisting of four main constructs:

- Self Awareness

- Self Management

- Social Awareness

- Relationship Management

These constructs can be considered the basis of work place proficiencies such as: communication skills, team work, influencing others, conflict resolution, personal effectiveness, working ethics, information literacy, reasoning, problem solving, technology skills and many more. The importance of these proficiencies should not be underestimated.

These soft skills or work place proficiencies incorporate a number of skills, categorized in a different category, with a variety of definitions. It would not be appropriate to list all related skills along with their variety of definitions here in this article. However, this study was focused on limited types of skills with specific definitions as provided below:

- Communication skills: An ability to make succinct presentations to a range of audiences about technical problems and their solution, involving face-to-face, written and also electronic communication (ACM \& IEEE, 2008).

- Leadership skills: An ability to lead others in a team, developing the sense of team purpose and direction to achieve the goals (Taylor \& Woelfer, 2009).

- Teamwork skills: An ability to work cooperatively and efficiently as part of a team (ACM \& IEEE, 2008, Taylor \& Woelfer, 2009).

- Emotional intelligence: An ability to carry out accurate reasoning about emotions and the ability to use emotions and emotional knowledge to enhance thought (Quinn-Hughes, Fisher, \& Dooling, 2008). One part of emotional intelligence is to exercise self control which is an ability to "maintain control over emotions and avoid negative actions under stress" (Taylor \& Woelfer, 2009).

In an analysis of a range of companies representative of diverse industries and organizations of different sizes and geographical distribution, it was found that, "Most of the organizations placed more emphasis on non-technical or soft skills" and "Consistent with earlier responses, suggestions for non-technical skills or knowledge outnumbered technical skills and knowledge more than two to one" (Benamati \& Mahaney, 2007). A study by Huang et al. (2009) differentiated between technical, business and humanistic job skills. Business skills included: problem solving, project management and ethics. Humanistic job skills included those typically categorized as soft skills such as: teamwork, leadership, ability to work with others. Using these categories an analysis of 241 on-line advertised jobs found that two humanistic skills (communication and writing) were referred to most often. Of the top ten skills, five were in the humanistic category. It was concluded that employers seek to recruit individuals that have the ability to communicate effectively in the business environment.

\section{Teaching soft skills}

The IT field encompasses a broad range of technical sub-disciplines such as: software development, database administration, and network engineering. Regardless of technical specialization, soft skills are a common denominator and need to be explicitly taught. According to the Joint Task Force on Computing Curricula, there 
are four main ways to incorporate non-technical skills in computer science curricula (Joint Task Force on Computing Curricula, 2001). These four methods are:

1. Non-technical skills units,

2. Senior year project units,

3. Team based project units, and

4. Internship programs.

There are advantages and disadvantages to teaching soft skills as dedicated non-technical units. Arguably it is better to each these skills in a technical context, however this may be problematic due to curriculum time constraints. McIntosh-Elkins and Klein (2008) described an initiative which integrates teaching of technical skills and training of non-technical skills throughout their program. This starts in the first year and allows students the opportunity to develop such skills over time. Results from a dedicated, interactive, multimedia-based communications skills course that taught writing, speaking and interpersonal communications rated the learning experience as high (Blume, Baecker, Collins, \& Donohue, 2009). However, this study indicated the difficulty of finding suitably qualified instructors with the following skill sets:

1. A graduate degree in English or closely related subject.

2. Experience teaching writing, public speaking, and interpersonal skills.

3. Strong organizational, interpersonal, and communication skills. and

4. Demonstrated evidence of excellence in teaching.

Such a skill profile is more readily available in countries that provide and encourage generic liberal arts courses. Such courses are common in the USA but not in many European countries (Blume et al., 2009). An extensive survey of graduates who had completed a three year degree in Australia found that "The graduates in employment have highlighted broad mismatches between the requirements of their professional work in these categories and the preparation for employment they received from university" (Koppi et al., 2009). There were various degrees of mismatch across all the categories: personal/interpersonal abilities, thinking/cognitive abilities, business abilities, technical abilities and learning abilities. However it is significant that graduate unpreparedness in soft skills may not be because the universities did not provide opportunities to develop these skills, but rather because students may not have appreciated the importance of such skills. Hence the students failed to take the opportunities provided to develop their soft skills fully. Understandably, if students have never been in full time employment they are unlikely to appreciate the dynamics of a working environment and hence employer expectations. This would suggest that team-based project units and internship programs may be of particular value. Capstone style senior projects, which combined multi-disciplinary team members from different study majors, have been successfully used for teaching non-technical skills because students from different disciplines need to be able to work together in an effective and collaborative manner (Brown, Lee, \& Alejandre, 2009). Internship programs directly expose students to workplace expectations and hence within some countries internships are a common aspect of IT courses. However within Australia internships are not common and there is a predisposition to substitute project-based courses.

\section{Research questions}

Within the context of an Australian university, this research focused upon a limited range of soft skills, namely communication skills, leadership skills and team working skills. This research did not include ethics, information literacy, reasoning and problem solving which could also be regarded as soft skills. A survey was answered by final year project students, to address the following questions regarding the teaching soft skills:

1. What is the preferred mode of delivery?

2. How should these skills be taught?

3. What difference, if any, exists between students with work experience and those without?

4. Which soft skills are considered to be of most importance to students?

5. What relative importance do students place on technical and non-technical skills?

\section{Research methodology}

A questionnaire was distributed to two different project student classes. The first group was enrolled on the Project Preparation Unit (PPU). This unit is a prerequisite to undertaking a team-based project. Accordingly this unit provides explicit instruction on topics that include: project proposal, project scope, planning and all associated topics concerned with successful project completion. Soft skills are not taught in this unit. On successful completion of the PPU, students undertake a semester-long team-based project. In order to provide exposure to a working environment, staff were allocated to student teams and also acted as clients. Hence the 
students are required to interview their clients and deliver according to the agreed specification in a given time frame. In this survey 18 students were enrolled in the PPU, from which there were 12 participants $(67 \%)$. These 12 students were undertaking projects in a range of different topics that included: software engineering, database development and computer network projects. These different projects were related to students' enrolled courses and their personal interests.

The second cohort of students were all enrolled in two Project Implementation Units (PIU1\&2). As such these students had successfully completed the PPU and were working in teams, typically of two or more students, and were working toward project completion. This cohort consisted of 20 students from which there were 14 participants $(70 \%)$. The statistical distribution regarding age, previous work experience and different enrolled courses of the students in both groups are displayed in Figure 1 by the number of participants and percentages.

\section{Results and discussion}

Q1: Which delivery mode is suitable for teaching soft skills in student opinions?

Significantly $96 \%$ of all participants agreed with learning soft skills from project based units (Figure 2). However it was considered important that the project should be as realistic as possible and provide students with the opportunity to implement a final working product.

Surprisingly $80 \%$ of all participants thought that a conventional lecture environment could be used to teach soft skills. And $65 \%$ of all participants considered role playing activities to be useful for teaching soft skills. This is concurrent with a study that demonstrated the value of board games to teach skills associated the complex and dynamic environment of project development (Linehan, Lawson, \& Doughty, 2009).

Even though all the participants were enrolled as full time, on-site students they were asked their opinion of the value of teaching soft skills in a purely on-line mode. The results were unambiguous - only $26 \%$ of participants considered this to be a satisfactory mode of learning.

Q2: How can non-technical skills be taught?

All participants were asked their preferred method by which soft skills should be taught. The most popular method ( $70 \%$ of respondents) was to teach soft skills as an integral part of a team-based project (Figure 3). Significantly over half of all respondents (56\%) thought that soft skills should be taught as an integral part of normal technical units. The authors suggest this is potentially a useful method to teach some of the more rudimentary soft skills such as report writing and other communication skills. Interestingly $54 \%$ of participants would prefer to have a single, dedicated soft skills unit with only $39 \%$ wanting more than one dedicated soft skills unit. Finally $9 \%$ of respondents thought soft skills can be developed by self-learning. Regardless of implementation method, either embedded or dedicated, the authors suggest the early implementation of this material. This will provide students with the opportunity to practice and develop their non-technical skills.

Q3: Are there any different preference in universities conducting non-technical skills unit for work experienced students, compared with students without -work experience?

Part-time students who are currently in employment may have a different perspective to students without any experience in the work force. Concurrent with the study by Koppi et al. (2009), the majority of the students with work experience (61\%) appreciated the value, importance and current methods of teaching non-technical skills (Figure 4). By contrast only $38 \%$ of students with no work experience valued the importance of non-technical skills. Clearly this is a problem that must be explicitly addressed.

Q4: Which kinds of skills do students value most?

A range of soft skills were selected and their relative importance evaluated by participants (Figure 5). The majority of students $(92 \%)$ ranked team-working as the most important non-technical skill. This was followed by communication (88\%), leadership (79\%) and lastly emotional intelligence (43\%).

Q5: How much are non-technical skills valued by students when compared to technical skills?

Participants were asked to evaluate the relative importance of technical and non-technical skills. Interestingly $64 \%$ of all participants thought that the employers place an equal value on them i.e. soft skills are of equal importance to technical skills. However $36 \%$ of the participants thought that employers rank soft skills more highly. Of this $36 \%$ the majority of the participants had work experience. Clearly those in employment appreciate the importance of soft skills in the work place. This may have been due to the differences between students being informed of the importance of soft skills by their lecturers and appreciating this via experience in the workplace or as part of a project. Hence the embedding of non-technical skills in course syllabi and stressing their importance may not be sufficiently believable for many of those students lacking workplace experience. 
In an attempt to address this problem, the network project students are given presentations by representatives from different companies. These presentations are not only technical but the speakers also indicate their expectations of potential recruits. Every industry speaker has indicated to students that soft skills are far more important than technical skills even though technical skill is obviously important.

\section{Conclusion}

A limitation of this study is the small sample size and further research is planned using a larger population. However, the results clearly indicated, from a student perspective, that soft skills must be taught on a face-to-face basis. Furthermore, whilst some of these non-technical skills can, and should, be taught in either embedded form or as separate units, a team-based project was of paramount importance. Significantly this preliminary study clearly demonstrates that student experience in the workplace is an important aspect of teaching soft skills. Without this experience students may not understand the importance of this type of instruction even though such skills are commonly embedded throughout the curricula. Internships are not the norm in Australia; and hence in an attempt to address this problem, representatives from companies are invited to give presentations to students.

\section{References}

Accreditation Board for Engineering and Technology (ABET). (2010). History of ABET. Retrieved 22nd January, 2011, from http://www.abet.org/history.shtml

Association for Computing Machinery, \& IEEE Computer Society. (2008). Computer Science Curriculum 2008: An Interim Revision of CS 2001 [Electronic Version]. Retrieved 2010, August 31, from http://www.acm.org//education/curricula/ComputerScience2008.pdf

Benamati, J. S., \& Mahaney, R. C. (2007). Current and future entry-level IT workforce needs in organizations. Paper presented at the Proceedings of the 2007 ACM SIGMIS CPR conference on Computer personnel research: The global information technology workforce.

Blume, L., Baecker, R., Collins, C., \& Donohue, A. (2009). A "communication skills for computer scientists" course. Paper presented at the Proceedings of the 14th annual ACM SIGCSE conference on Innovation and technology in computer science education.

British Computer Society. (2010). Syllabus - diploma in IT. Retrieved December 20th, 2010, from http://www.bcs.org/server.php?show=ConWebDoc. 12058

Brown, Q., Lee, F., \& Alejandre, S. (2009). Emphasizing soft skills and team development in an educational digital game design course. Paper presented at the Proceedings of the 4th International Conference on Foundations of Digital Games.

Daniels, M., Cajander, A., McDermott, R., \& von Konsky, B. (2011). Assessing professional skills in engineering education. Paper presented at the Australasian Computing Education Conference (ACE 2011), Perth, Australia.

Goleman, D. (1998). Working with emotional intelligence. New York: Bantam books.

Huang, H., Kvasny, L., Joshi, K. D., Trauth, E. M., \& Mahar, J. (2009). Synthesizing IT job skills identified in academic studies, practitioner publications and job ads. Paper presented at the Proceedings of the special interest group on management information system's 47th annual conference on Computer personnel research.

Joint Task Force on Computing Curricula. (2001). Computing Curricula 2001: Computer Science [Electronic Version], from http://www.acm.org/education/education/education/curric_vols/cc2001.pdf

Koppi, T., Sheard, J., Naghdy, F., Chicharo, J., Edwards, S. L., Brookes, W., et al. (2009). What our ICT graduates really need from us: a perspective from the workplace. Paper presented at the Australasian Computing Education Conference (ACE 2009), Wellington, New Zealand.

Linehan, C., Lawson, S., \& Doughty, M. (2009, 23-24 March 2009). Tabletop prototyping of serious games for 'soft skills' training. Paper presented at the Games and Virtual Worlds for Serious Applications, 2009. VS-GAMES '09. Conference in.

McIntosh-Elkins, J., \& Klein, R. (2008). Creating pathways to develop student professionalism: a new direction. Paper presented at the Proceedings of the 36th annual ACM SIGUCCS conference on User services conference.

Quinn-Hughes, K. D., Fisher, D. J., \& Dooling, C. (2008). Blaze a new trail to success with emotional intelligence. Paper presented at the Proceedings of the 36th annual ACM SIGUCCS conference on User services conference. 
Schutte, N. S., Malouff, J. M., Hall, L. E., Haggerty, D. J., Cooper, J. T., Golden, C. J., et al. (1998). Development and validation of a measure of emotional intelligence. Personality and Individual Differences, 25(2), 167-177.

Taylor, H., \& Woelfer, J. P. (2009). Critical skills for IT project management and how they are learned. Paper presented at the Proceedings of the special interest group on management information system's 47th annual conference on Computer personnel research.

Underwood, A. (1997). Core body of knowledge for information technology professionals. Retrieved December 20th, 2010, from http://www.acs.org.au/index.cfm?action=show\&conID=cbok\#4

Yuan, D., \& Zhong, J. (2010). Developing and evaluating a network curriculum to meet ABET accreditation and IT industry needs. J. Comput. Small Coll., 26(2), 256-262.
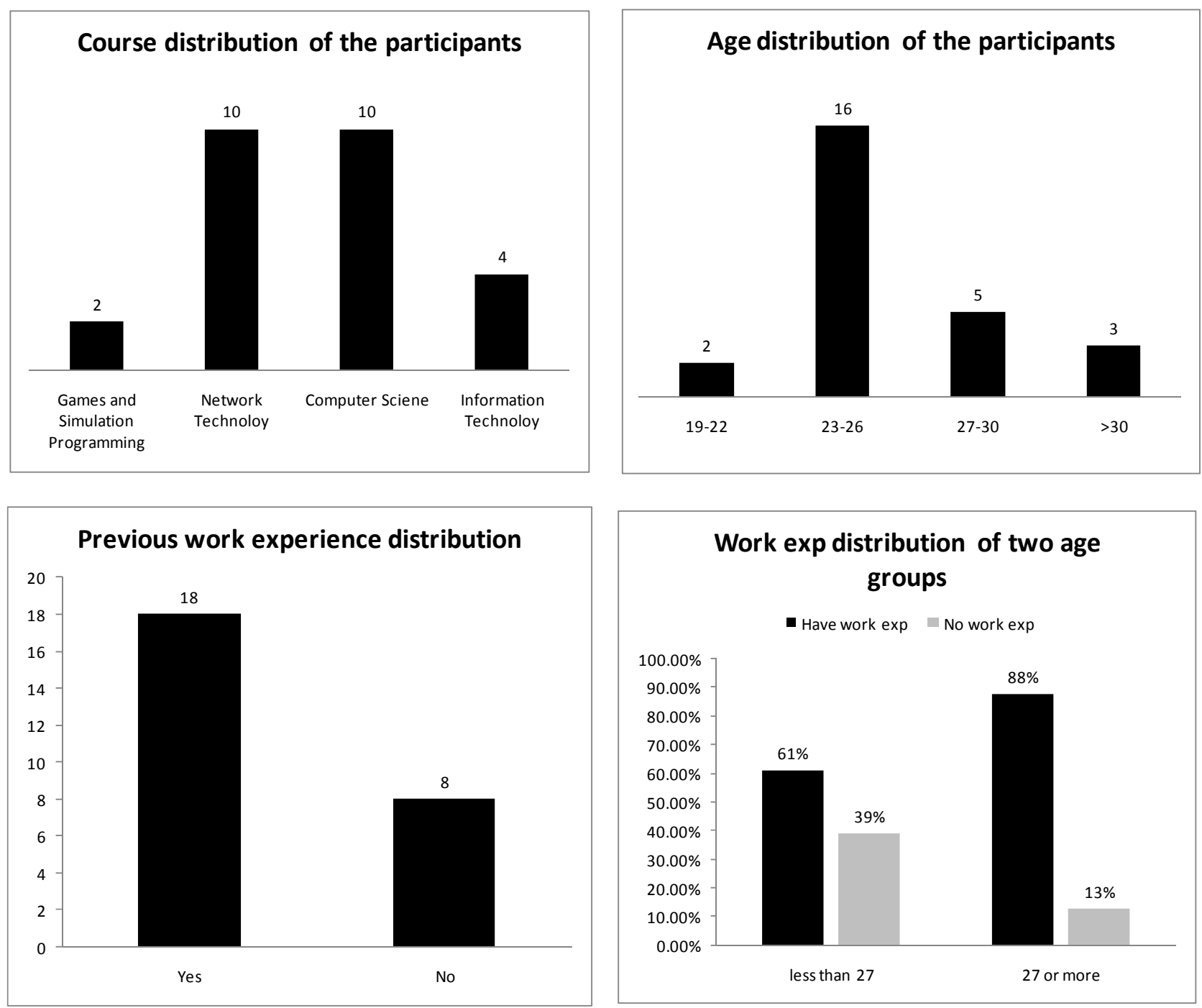

Figure 1. Statistics of the survey participants 


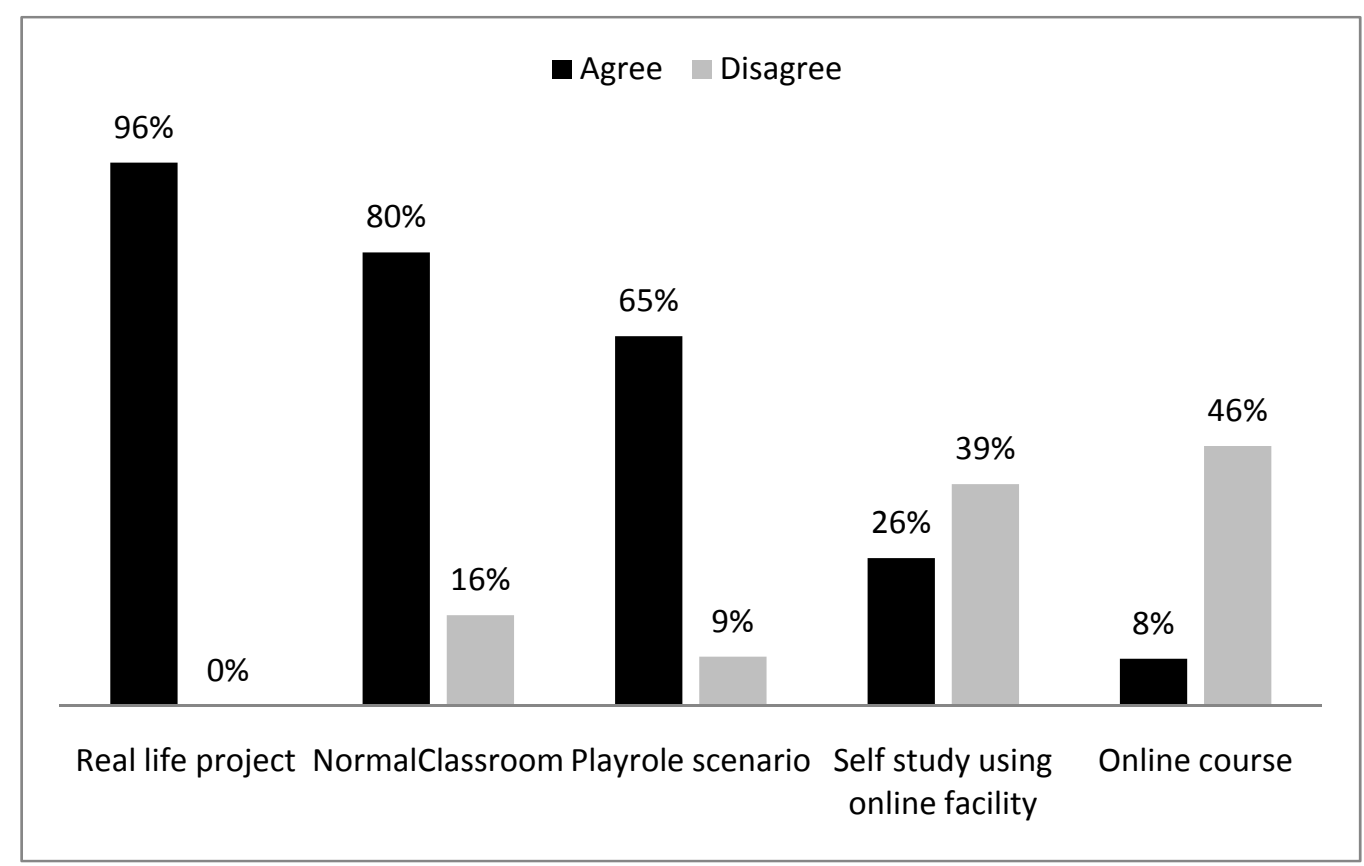

Figure 2. Delivery mode preferences for non-technical skills units

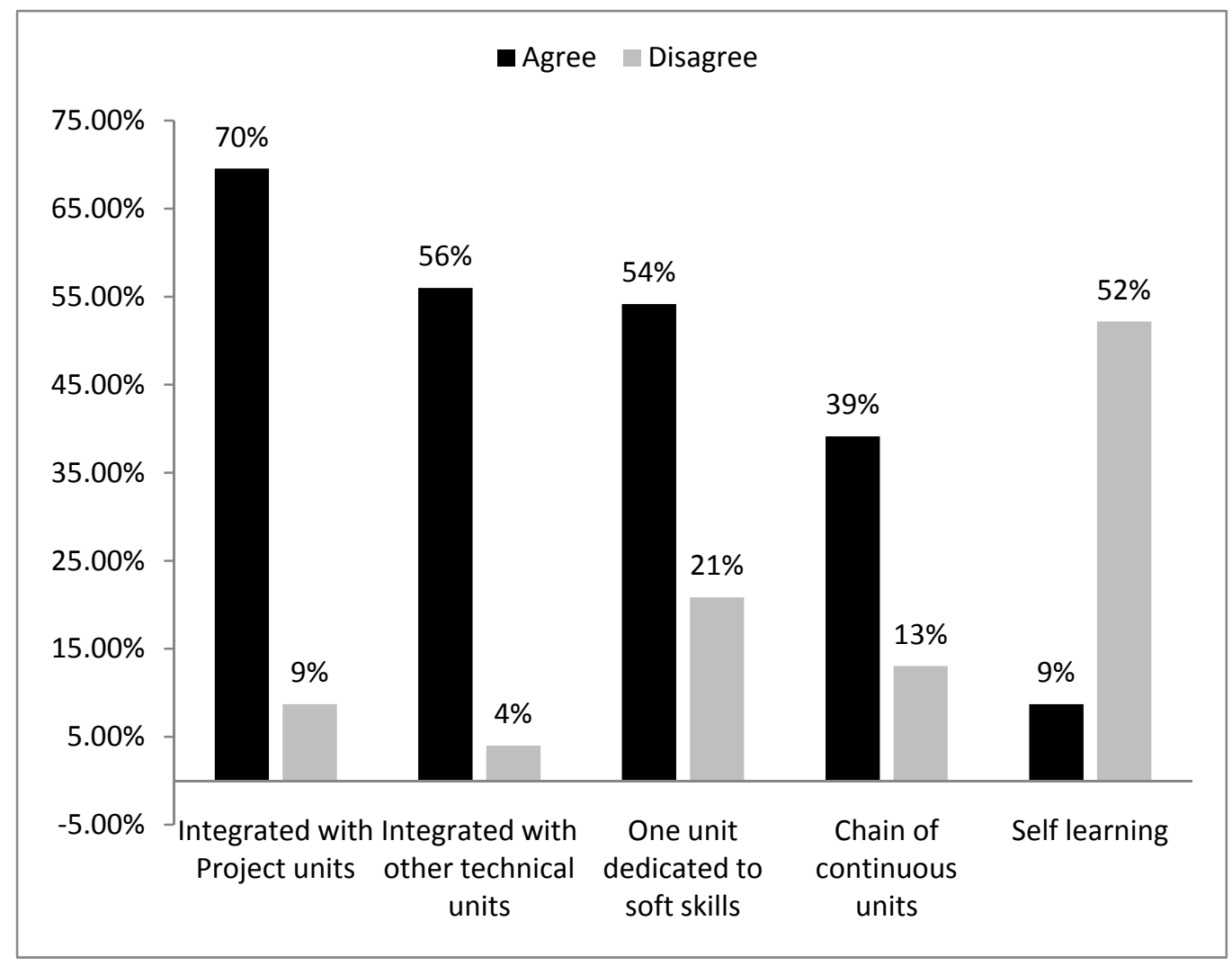

Figure 3. Preferences of how non-technical skills could be taught 


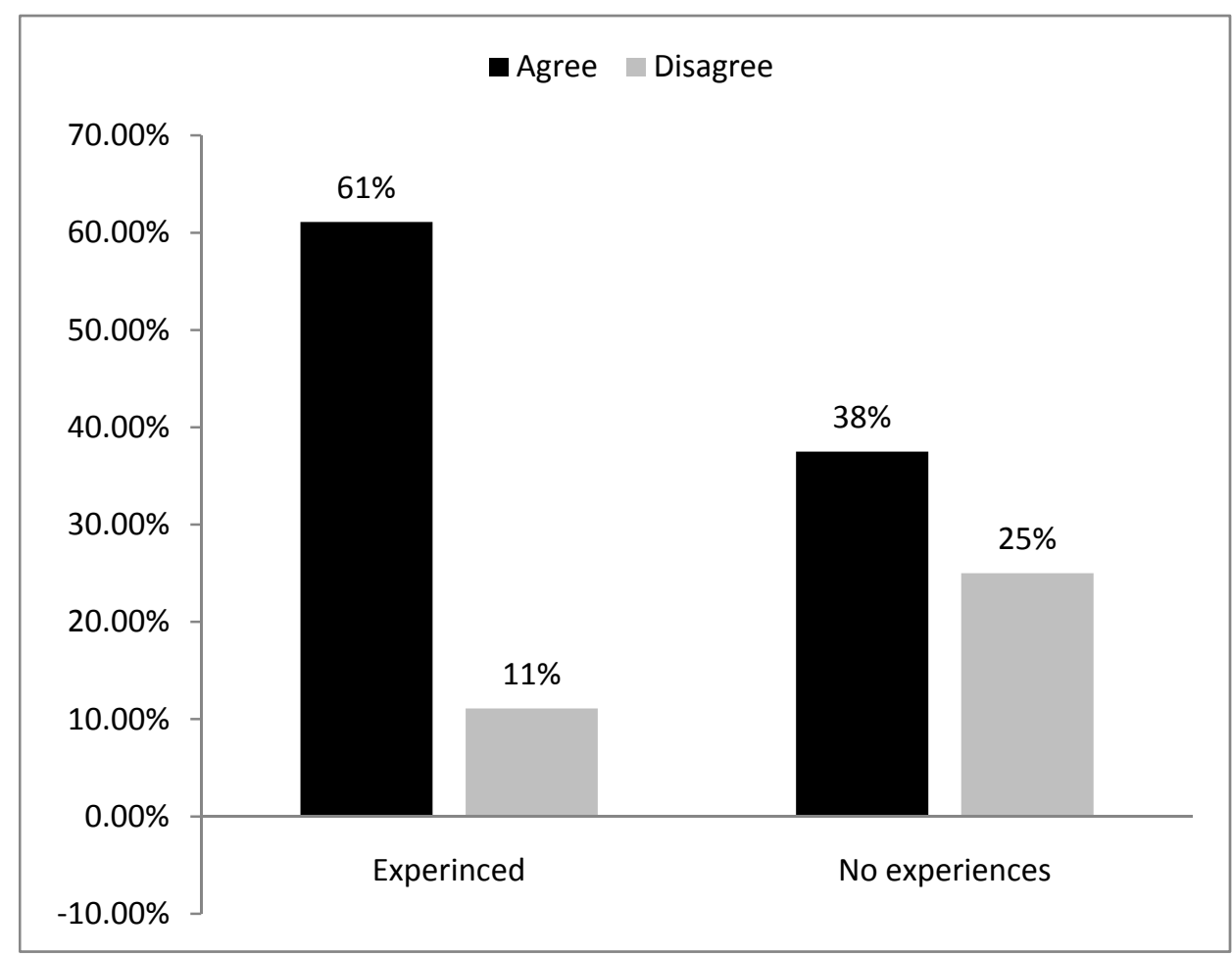

Figure 4. Percentage of respondents with work experience comparing with no work experience toward the current university curricula

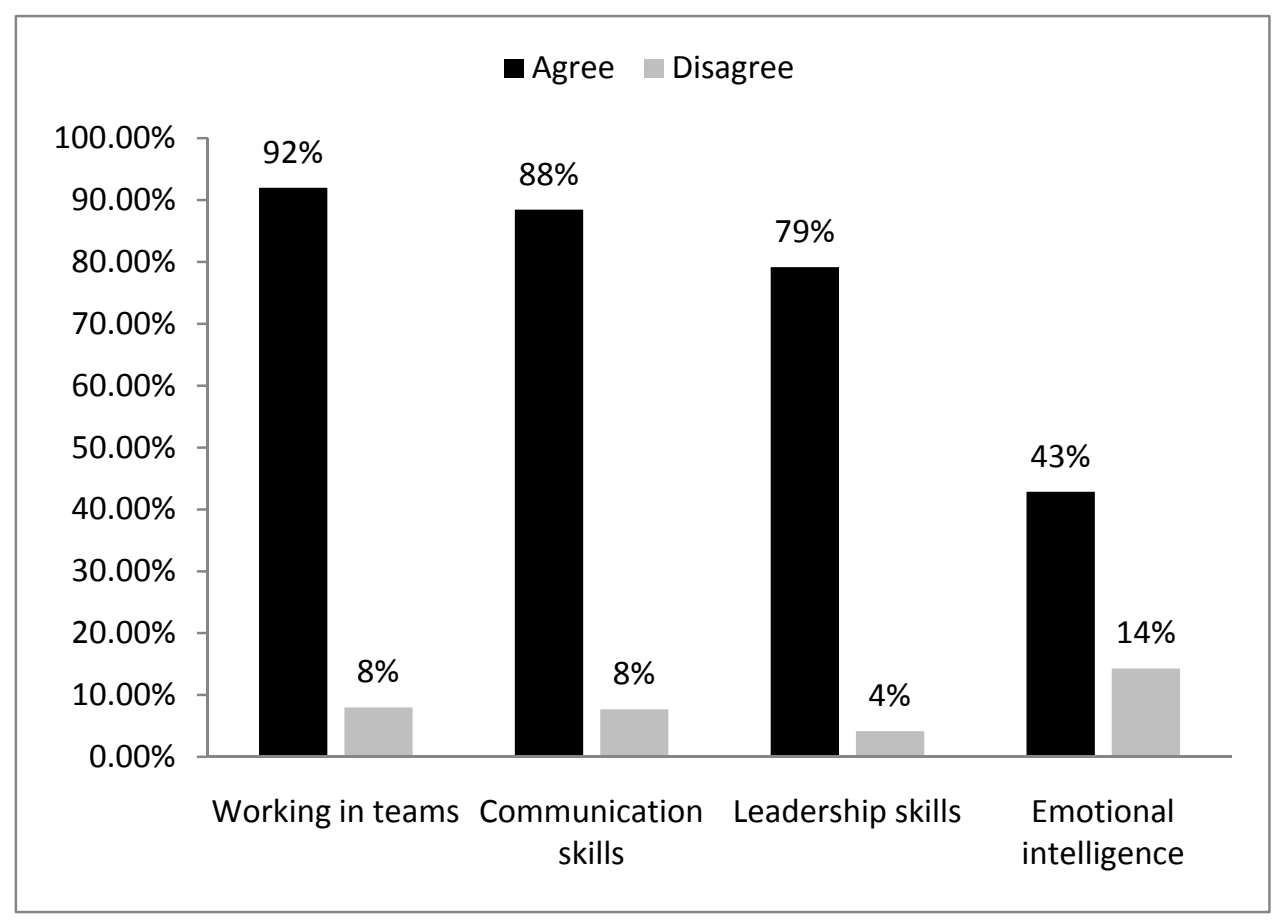

Figure 5. The relative importance of soft skills evaluated by participants 